\title{
Analysis of pedestrian accidents using a geographical information system (GIS) in Konya city, Turkey
}

\author{
C. Avc1 \& S. S. Durduran \\ Department of Geomatic Engineering, Selcuk University, Turkey
}

\begin{abstract}
Traffic accidents occur due to people, vehicles and the environment. They are caused by drivers' carelessness, excessive speed, because of, for example, human failings and a mechanical glitch occurring in vehicles, and environmental factors such as heavy fog or snowy weather. Therefore, to minimize traffic accidents, multi-faceted measures have to be taken. In order to avoid irreversible losses three parameters are separately focused upon. One of the parameters is of a person who is located in traffic as a driver or passenger in a vehicle, or outside of the vehicle as a stationary or moving pedestrian. In this study pedestrian accidents which occurred between the years 2005-2006 and 2011-2012 will be discussed. Using GIS technologies, spatial analysis will be performed and, in order to focus attention on the environment, an attempt to achieve check out measures from different perspectives will be made. Also in this study the decisions with outcomes will be evaluated on a spatial basis so as to create a base in order to be more effective.

Keywords: GIS, pedestrian accidents, spatial analysis.
\end{abstract}

\section{Introduction}

In parallel with the increasing technology and population, the rapid increase in the number of vehicles - in Turkey and worldwide - has led to an increase in the number of traffic accidents. According to the statistical data of the General Directorate of Security Affairs, the top three causes of severe accidents and injuries occurring in Turkey are driving too fast, not wearing seat-belts and pedestrians. Among the factors determining the occurrence of accidents, the environment of transportation, the infrastructure of highways, the management, 
inspection and application of traffic, the attitudes of the people on the road (drivers-pedestrians-passengers) and environmental conditions can be listed. In addition, passengers are the group who are affected most during accidents.

Every year, all over the world, 50 million people are injured in accidents and 1.2 million people are killed. $2 \%$ of all deaths and $23 \%$ of deaths due to injuries are related to traffic accidents. $50 \%$ of the people who are killed in accidents are innocent people such as passengers and pedestrians [1]. Pedestrians who have major roles in traffic accidents both cause the accidents and are affected the most in those accidents. In this study, the statistical data of accidents which the pedestrians encounter in the province of Konya on a street basis will be processed in a computer environment; a comparison of the accidents will be examined thoroughly on the basis of years. The accidents which were numerically found will be visualized on the basis of places and with a basemap which was generated with the help of the implementation of various analyses focusing on pedestrian accidents that occurred in traffic.

\section{Materials and methods}

The field of study is the province of Konya which is one of the oldest settlement areas in Turkey and is located in the middle of the Anatolian Peninsula.

In this study, the data of reports of accidents involving pedestrians issued by the Traffic Division of the General Directorate of Security Affairs, Konya for the years 2005-2006 and 2011-2012 were used. It is obvious that traditional methods fail in preventing traffic accidents and new methods are needed. For that reason, developing computer technologies should be used. Benefits from new technologies in order to help policy-makers provide safe transportation will lead to more sensitive and accurate results. At this point, the geographical information system (GIS) emerges as a technology which can produce effective solutions related to the processing, storage and analysis of data, and the submission of its results to users. With the development of GIS software which is functional and easy to use, GISs have begun to be used in every field and have become a necessity. Some of these developments have taken place in parallel with developments in the computer industry. The starting point of this change is the rapid increase in computer technology. The broadening of the area of utilization and its contribution to users and administrators prove the availability of the GIS [2]. In recent years, it has commonly been used in transportation, because a GIS can be used as an effective tool to produce a rational solution for urban management and traffic planning [3].

The use of a GIS in transportation systems has made significant contributions to increased productivity in the following.

- The analysis and management of accident reports;

- The planning and management of bus routes;

- The tracking of buses and emergency states;

- The automatic determination and tracking of vehicles (Automatic Vehicle Location (AVL)); 
- Traffic observation systems;

- The inventories of buses;

- The management of rail systems;

- Communication of energy use and its management;

- The revision of bus routes according to demographic analysis;

- The planning and management of transportation [4].

\section{Application}

The population of the province of Konya, which was determined in accordance with the address-based population registration system, in 2012 was 2,052,281. The annual population growth was $6.71 \%$ and the population per $\mathrm{km}^{2}$ was 53 persons. While the urbanization rate of the province in the year 2000 was $59 \%$, that of 2012 was $76.20 \%$ [5]. Thus, the quantity of traffic accidents and the precautions against accidents have increased due to the increase in the population and the urbanization. The data of this study includes the years 2005, 2006, 2011 and 2012. The source of the data used in the study is the Traffic Accident Reports; these reports were examined and the data was computerized. Consequently, the data was separately evaluated in a GIS. In the evaluation, the traffic accidents involving pedestrians that had taken place in the provincial centre of Konya were discussed in detail and the changes each year pointed out. The accident data of the years 2005, 2006, 2011 and 2012 relating to the accidents that took place in the avenues and streets were obtained from the Konya Traffic Inspection Division. In order to perform the spatial analysis of traffic accidents, geometric data of the study area is also needed. For that reason, an Online Basemap of the ArcGIS 10 software package and a map of Konya with a scale of $1 / 20000$ were used for the mapping data, which was used as a geometrical base. ArcGIS 10, a GIS software package, and "Street" maps were used as an online basemap, and the data of the accidents was transferred to a database environment. At the same time, this online basemap was matched with the coordinate transformation $1 / 20000$ scale map and the definitions were performed through vector road data and the accidents were pinpointed on every piece of the defined road and marked on the map.

The data was organized in order to match the verbal data, and the geometrical data was combined through the ArcGIS 10 software so as to perform effective interrogation.

With the help of satellite images, which were used as an online basemap, and ArcGIS 10, the accidents occurring on the roads were expressed both graphically and verbally; thus, interrogation was made possible (fig. 2).

A column bar chart was formed on the maps which provided us with a clear vision of the distribution of the accidents occurring on the streets each year; thus, the changes were clearly seen (fig. 3). 


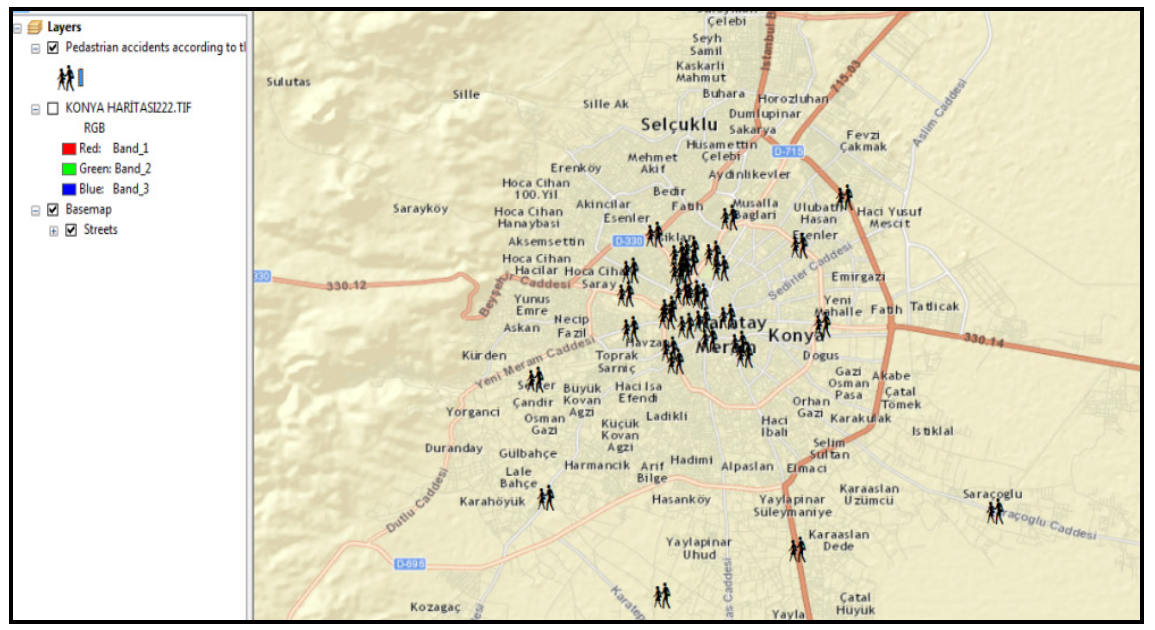

Figure 1: The map of pedestrian accidents in the provincial centre of Konya.

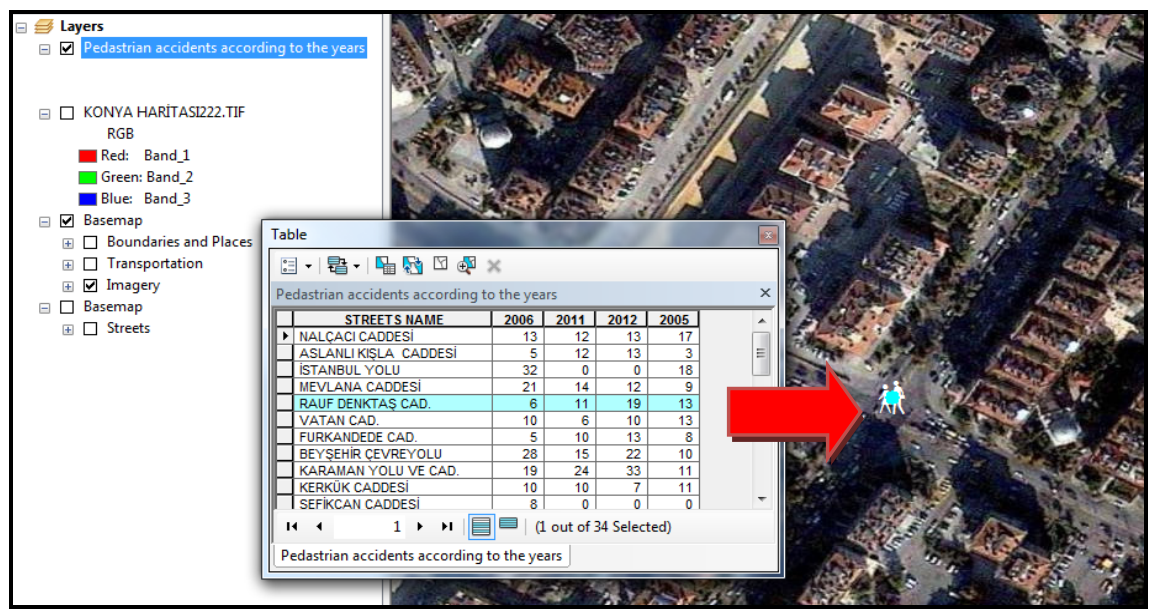

Figure 2: The pedestrian accidents which took place in the provincial centre of Konya and data of the feature.

In order to produce the density map of accidents occurring in the years 20052006, a geostatistical IDW method was used. The areas where the accidents occurred densely in the years 2005-2006 were shown in red while the areas with fewer accidents were shown in blue and the intermediate values were expressed in yellow, orange and light blue; the accident analysis of pedestrians in the province of Konya were spatially formed (fig. 4). 


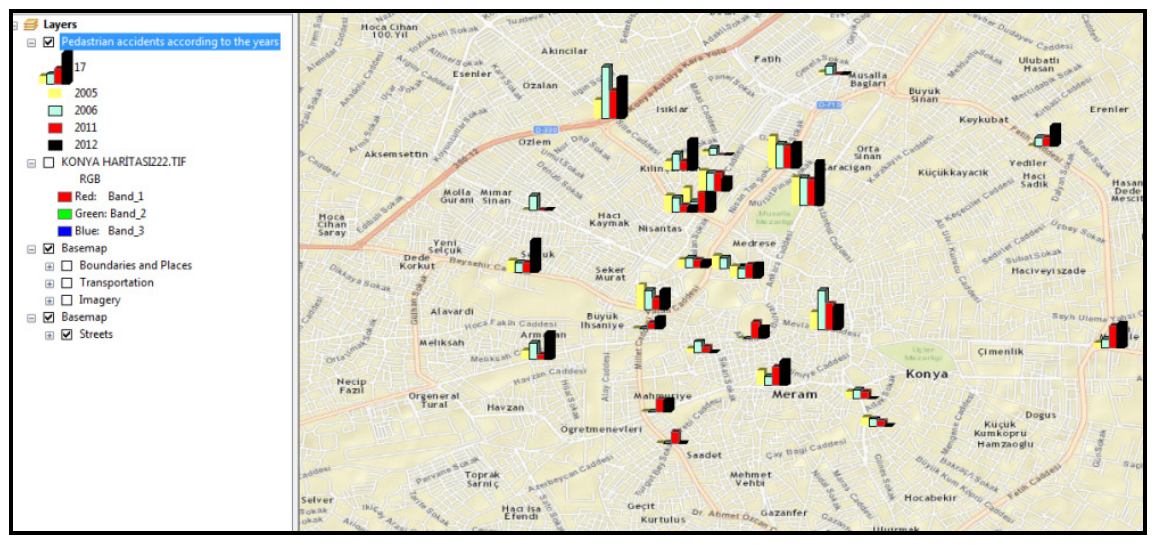

Figure 3: Pedestrian accidents for each year which occurred in the provincial centre of Konya.

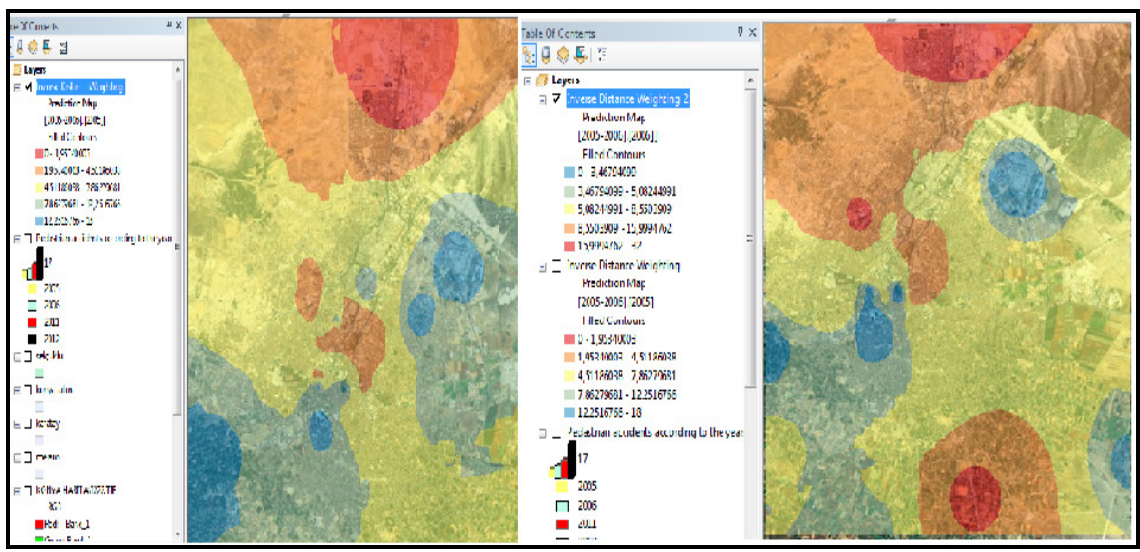

Figure 4: The density map of pedestrian accidents occurring in the provincial centre of Konya in the years 2005-2006.

The density map of pedestrian accidents for the years 2011-2012 was similarly formed using the geostatistical IDW method. The areas where the accidents occurred densely were shown in red while the areas with less density were shown in blue and the intermediate values were shown in yellow, orange and light blue; the accident analysis of pedestrians in the province of Konya were spatially formed (fig. 5). 


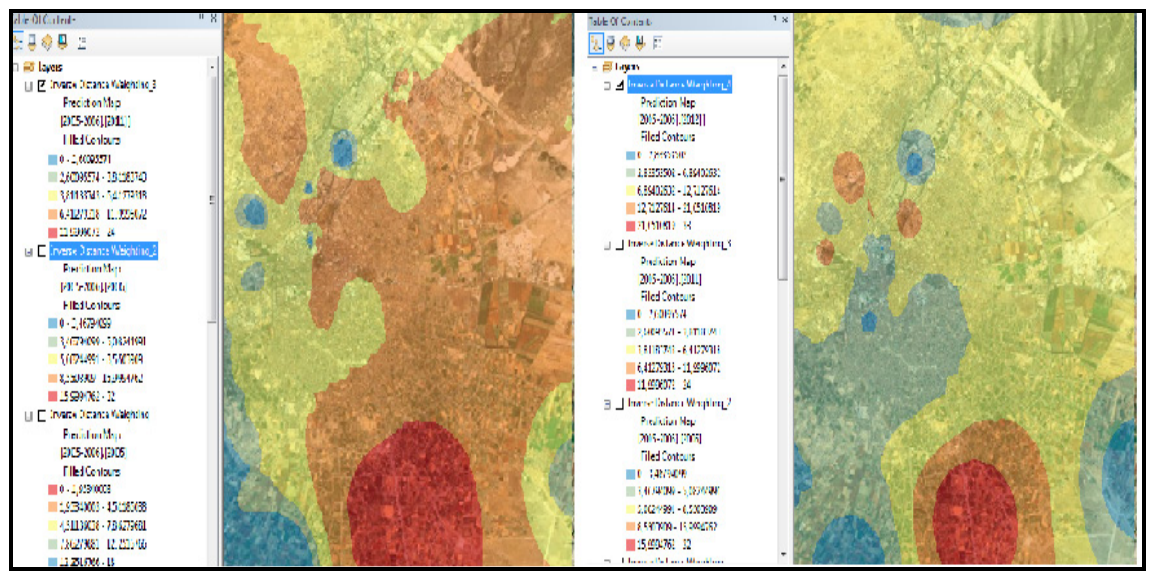

Figure 5: The density map of pedestrian accidents occurring in the provincial centre of Konya in the years 2011-2012.

\section{Conclusion}

In conclusion, the data was transferred through quantification into the environment of a GIS, using Konya maps, and the pinpointed data was used to form a system that enables interrogation and analysis. The factors affecting the traffic accidents vary according to time and place. For that reason, a solution which is convenient may be inappropriate in another place or may be more effective. In order to produce more realistic solutions for traffic accidents, which have a complex structure, the evaluation of accidents will be carried out over the years with the help of GIS maps which are obtained in Konya. The density of pedestrian accidents occurring in the years 2005 and 2006 had approximate values from spatial and numerical aspects. In 2005, pedestrian accidents were found to be dense in Yazır, Sancak and Karaaslan Dede regions of the Selçuklu district while those of 2006 were found to be dense in the Issılar region as well as the Yazır, Sancak and Karaaslan Dede regions. The density of the pedestrian accidents occurring in 2011 and 2012 have spatially and numerically similar values; the number of accidents were found to be greater than those in 2005 and 2006, and an increase was seen even in the years 2011 and 2012. In 2011, the pedestrian accidents were dense in Iş1klar and Karaaslan Dede districts while those in 2012 were found to be dense in Iş1klar and Karaaslan Dede districts. The high density of pedestrian accidents which occur in almost the same places clearly show that necessary precautions are not being taken in those regions. This situation draws attention to the importance of using a GIS and the importance of statistics which were spatially performed. Preparing the maps of the accidents and sharing them with the community during the training aimed to give effective protection against accidents, with discussion of the location, reason and form of the accidents, and the precautions to be taken against them. Giving training in accident prevention, performing inspections at necessary frequencies and 
providing information are effective in preventing accidents. The main point here is to create an awareness in individuals about what they can do to avoid accidents. According to the results obtained, the main reasons for accidents are a lack of traffic inspections, delinquency of people who utilize roads as driverspedestrians-passengers who do not abide the rules, insufficiency of the transport infrastructure, mistakes related to the transportation organization of the country, rapid urbanization, insufficient deterrence of the fines and punishments, malfunctions related to first aid, and lack of information. In this study, an increase was determined in the pedestrian traffic accidents in the regions of Yazır, Sancak, Işıklar and Karaaslan Dede, which have dense population rates when evaluated each year, but a high density of traffic accidents in the same regions has drawn attention to these regions. Necessary investigations should be carried out in the determined regions and also precautions should be taken. As soon as possible, the loss of life and accidents should be minimized. The data from the GIS database to be established and the statistical data which can be obtained from the analysis of the accidents may be used and the obtained maps could be used as an effective basemap in the determination of the real causes of the accidents.

\section{References}

[1] World Health Organization (WHO) Global Status Report on Road Safety: Time For Action, Geneva 2009

[2] Güvenal B., Çabuk A., Yavuz M. İ., Trafik Kazalarının Azaltılması Amaciyla Coğrafi Bilgi Teknolojilerinden Yararlanılması, 4.Coğrafi Bilgi Sistemleri Bilişim Günleri, Fatih Ünv., İstanbul, pp. 2, 2006

[3] Durduran S.S., Alkaya C., Durduran Y., Avc1 C., 2012 Konya İlinde 0-15 Yas Grubu Çocukların Karıştığı Trafik Kazalarının Coğrafi Bilgi Sistemi Yardımıyla Mekansal Analizi ve Halk Sağlığı Açısından Önemi, 3. Karayolu Trafiği Sempozyumu ve Sergisi, Ankara, 16-18 May 2012

[4] Stillwell J., Geertman S., Openshaw S., Geographical Information and Planning, Springer, Berlin, pp. 350, 1999

[5] Konya Governorship, http://www.konya.gov.tr 